subset of the available alternatives.

But there may be an easier solution. Non-special states lead to such absurdities as alive-and-dead cats. Why not take this as a demonstration that these states are not really possible after all? This would leave the (now misnamed) special states as the only options, and would leave nothing for future conditions to explain.

The link between time's arrow and quantum measurement might thus be less close than Schulman suggests. Nevertheless, his book is essential reading for anyone with a serious interest in either topic.

Huw Price is in the School of Philosophy,

University of Sydney, NSW 2000, Australia.

\section{Faulty weather}

\section{Tectonic Uplift and Climate Change}

edited by W. F. Ruddiman

Plenum: 1997. Pp. 535. \$115, £83.64

\section{Jean-Pierre Burg}

There is a surrealist French song that laments the impossible love between a fish and a bird. It is a poetic stance reflecting that until recently the 'material' earth and the 'immaterial' atmosphere were thought to be worlds even more estranged than scientific orthodoxy suggested.

But Charles Lyell believed that the creation of recent mountains influenced the climate. Since then, modelling using nonclassical statistics has opened up previously unimagined horizons. If a butterfly flapping its wings in the Amazon forest can trigger frightful storms over Europe, is it so hard to accept that a rising mountain has its own climatic might?

W. F. Ruddiman has put together a wellintegrated answer for scholars and graduate students. It is built on geological information, palaeoclimatic records, ideas developed from a detailed knowledge of elevated regions and surrounding areas, and numerical modelling. The authors provide the pertinent yet equivocal evidence behind the hypothesis linking uplift with climate, and subsequent controversies.

Large-scale topographic changes result from tectonic convergence or extension and subsequent isostatic compensation. In the first chapters, three examples (South-East Asia, the central Andes and east Africa) provide information about the long-term links between global climate and the uplift of large areas. Elevated plateaux and collisional mountains are physical obstacles to wind and oceanic circulation. Over the past year El Niño has reversed its course, providing a timely reminder of the short-term effects of circulation changes.

The importance of numerical experiments for understanding geologically relevant effects is developed in the next chapters,

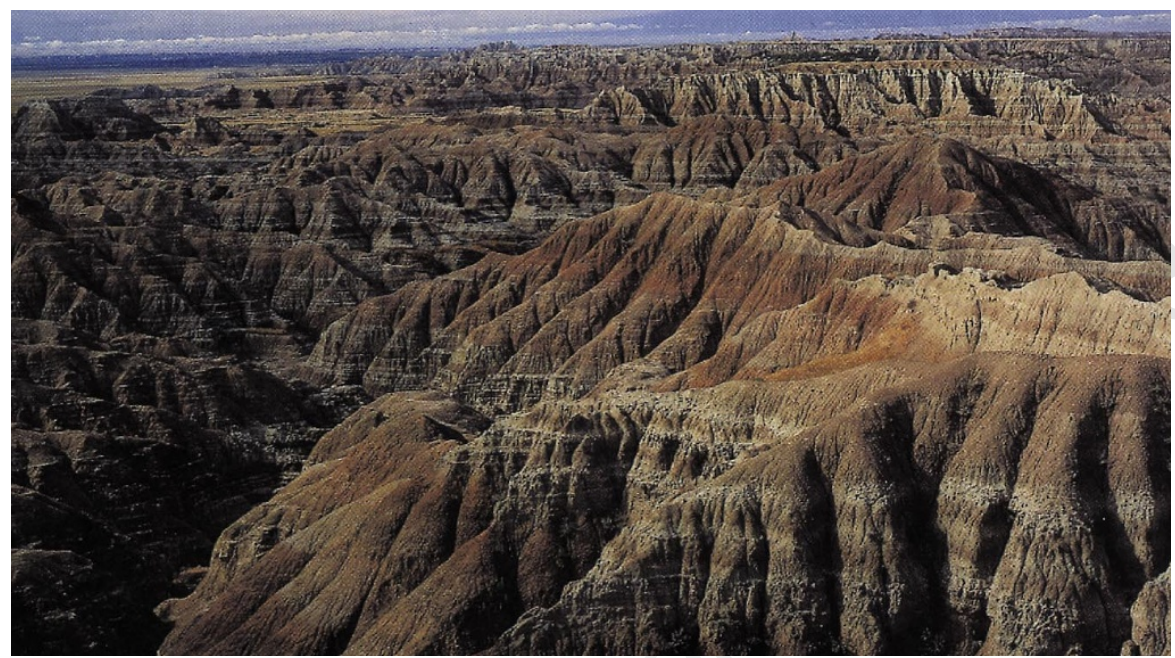

Gully erosion in the badlands of South Dakota. From the second edition of Understanding Earth by Frank Press and Raymond Siever (W. H. Freeman, \$62.95, £25.95, pbk; see Nature 370, 261; 1994).

which are mostly original in content. Theoretical knowledge gained from atmospheric sciences, applied to problems over large scales of time and space, helps to isolate the effects of mountains from other climatic components.

Many readers will learn that the unusually high present-day mountains can cause drying of mid-latitude continental regions. Many more will be intrigued by the relationship between orographic changes, resulting from increased physiographical gradients, and changes in the carbon cycle. Indeed, more than half of the volume deals with the balance between the rates of physical weathering - which includes orographic changes and thus the drainage capacity of high mountainous terrains — and chemical weathering - which includes the effects of dissolved loads in rivers and their capacity to extract from rocks the chemical elements that control oceanic and atmospheric compositions. These factors have an indirect but extensive effect on the global climate, mostly through the greenhouse effect.

Because of its size, the Tibet-Himalaya region is an important case study. Its effect on the climate of the Northern Hemisphere seems certain. But how does a rising region increase erosion, alter global circulation and affect seasonal distribution and contrasts? Why might these modifications increase global mean rates of chemical weathering, which could reduce cardon dioxide levels and thus further affect the climate, and so on?

Scientists will get ideas from reading this book. They will also find interdisciplinary research that has been successful in stimulating new thought and targeting important issues, and which emphasizes the role of such interdisciplinary research in science today.

Einstein argued that time and space are like a theatre performance: the action starts from nothing, then the relationship between the actors defines the stage. Similarly, tectonics and global changes are intricately associated to enliven our planet.

A few years ago, Tectonic Uplift and Climate Change would have been a sciencefiction title, if not a heresy. Today, and thanks to syntheses such as this, we suspect that there may be more than a casual relationship between the evolving topography and the climate.

Jean-Pierre Burg is at the Geologisches Institut, ETH Zentrum, Sonnegstrasse 5, CH-8092 Zürich, Switzerland.

ADVERTISEMENTS 